\title{
Comparación de técnicas in vitro para detectar resistencia de Plasmodium falciparum a medicamentos
}

\author{
Jacqueline Chaparro' ${ }^{1}$ Moisés Wasserman ${ }^{2}$
}

\begin{abstract}
Resumen
Debido a que la resistencia de Plasmodium falciparum a medicamentos se percibe como uno de los problemas que más agrava la situación de la malaria en Colombia, existe la necesidad de implementar procedimientos que permitan hacer una búsqueda amplia y confiable de resistencia para establecer la prevalencia y la variación del fenómeno al nivel epidemiológico. En este trabajo se estableció la resistencia de varias cepas de referencia y algunos aislamientos de campo de $P$. falciparum a medicamentos como cloroquina, amodiaquina, mefloquina, quinina, halofantrina, pirimetamina y sulfadoxina. La búsqueda de resistencia se hizo a través de cuatro estrategias experimentales: una prueba modificada en nuestro laboratorio, eficaz para detectar resistencia a varios medicamentos de manera simultánea (prueba radiométrica); ensayos de PCR para detectar el polimorfismo de la región 3' del gen pfmdr1 (gen de resistencia múltiple a medicamentos de P. falciparum) asociado con resistencia a cloroquina; ensayos de PCR para detectar mutaciones en la dihidrofolato reductasa (DHFR) y en la dihidropteroato sintetasa (DHPS), relacionadas con resistencia a pirimetamina y sulfadoxina respectivamente, y una técnica modificada por nosotros para establecer resistencia a cloroquina (Rapid-test). Se estableció que el ensayo más adecuado para hacer una búsqueda de resistencia in vitro a medicamentos es el PCR. Infortunadamente, aun se desconocen las bases moleculares de la resistencia a varios de los antimaláricos empleados y esto hace que la prueba radiométrica sea la mejor alternativa para detectar, a escala epidemiológica, la resistencia in vitro a cloroquina, amodiaquina, mefloquina, quinina y halofantrina.
\end{abstract}

Palabras clave: antimaláricos, resistencia, Plasmodium falciparum, gen de resistencia multiple a medicamentos, dihidrofolato reductasa, dihidropteroato sintetasa, prueba in vitro, Rapid-test.

\section{Comparison of in vitro techniques for the detection of Plasmodium falciparum resistance to drugs}

\section{Abstract}

Plasmodium falciparum causes the most severe form of human malaria, resulting in 2.7 million deaths throughout the world last year. The major control for this disease is through chemotherapy but the treatment has been complicated by the emergence of resistance

\footnotetext{
1 Investigador científico, Grupo de Bioquímica, Instituto Nacional de Salud. Santafé de Bogotá, D.C., Colombia.

2 Profesor, Facultad de Ciencias, Universidad Nacional de Colombia; investigador científico, Grupo de Bioquímica, Instituto Nacional de Salud, Santafé de Bogotá, D.C., Colombia.
}

Recibido febrero 13 de 1999 , aceptado junio 18 de 1999 
to most of the currently available antimalarials; this situation shows the necessity of mapping resistance and for defining the relationship between drug usage politics and the spread of resistance. In this paper four techniques are compared: a modified radiometric micro-test for detecting resistance to several drugs and the modification made to a test used for establishing chloroquine resistance (Rapid-test) is explained. The use of PCR assays to detect pfmdr1 gene polymorphism ( $P$. falciparum multidrug resistant gene) associated with chloroquine-resistance and to detect DHFR (dihydrofolate reductase) and DHPS (dihydropteroate synthetase) mutations related to pyrimethamine and sulfadoxine resistance is also demonstrated. Results suggest that the PCR assay is the most convenient approach. However, the use of the modified microtest for the determination of resistance to the quinine-like antimalarials is recommended because the molecular basis of their resistance to drugs remains unknown.

Key words: Antimalarials, resistance, Plasmodium falciparum, multidrug resistance gene, dihydrofolate reductase, dihydropteroate synthetase, Rapid-test, micro-test.

\section{Introducción}

La malaria es aún una de las enfermedades parasitarias que produce mayor morbilidad y mortalidad en el mundo; en años recientes, se han presentado aproximadamente 400 millones de casos y cerca de 2,7 millones de muertes (1). Aunque una de las estrategias de control más eficientes ha sido la quimioterapia, se ha producido un serio problema de salud debido a la aparición de parásitos resistentes a muchos de los compuestos usados para el tratamiento y profilaxis de la enfermedad (2-4); esta situación ha llevado a diseñar nuevos compuestos, por lo general, más costosos y menos efectivos, a los que el parásito eventualmente también ha desarrollado resistencia (5). El planteamiento de estrategias eficientes para controlar la malaria requiere de un conocimiento preciso de los niveles y distribución geográfica de parásitos resistentes a medicamentos; este acercamiento solo puede hacerse a través de ensayos diagnósticos de resistencia que permitan establecer esos parámetros de manera confiable. En este trabajo se compararon las técnicas in vitro más utilizadas para detectar resistencia de $P$. falciparum a medicamentos y se estableció la utilidad de cada una de ellas como herramienta en la búsqueda de resistencia a escala epidemiológica.

Las técnicas usadas fueron cuatro. Primero, un ensayo radiométrico modificado en nuestro laboratorio, eficaz para detectar resistencia a varios medicamentos simultáneamente. La prueba mide la inhibición del desarrollo (determinado a través de la inhibición de la incorporación de $\mathrm{H}^{3}$-hipoxantina) de parásitos sometidos a diferentes concentraciones de cloroquina, amodiaquina, mefloquina, quinina, halofantrina o de la combinación pirimetaminasulfadoxina $(6,7)$. Segundo, una técnica modificada por nosotros para establecer resistencia a cloroquina, basada en el eflujo diferencial del medicamento en parásitos resistentes y en parásitos sensibles (Rapid-test) $(8,9)$. Debido a que el verapamil inhibe el mecanismo de rápido eflujo de cloroquina, típico de parásitos resistentes (10-12), el carácter sensible o resistente se puede establecer con base en la acumulación de cloroquina en presencia y ausencia de verapamil. Tercero, ensayos de PCR para detectar resistencia a cloroquina. A pesar de la gran controversia que ha existido sobre las bases moleculares de la resistencia de $P$. falciparum a la cloroquina $(13,14)$, en 1990 se diseñó una prueba de PCR para detectar el polimorfismo de la región 3' no traducible del gen pfmdr1 (gen de resistencia múltiple a medicamentos de $P$. falciparum, (15). Se encontraron dos tipos de polimorfismo (K1 y 7G8) asociados con resistencia a la cloroquina y diversos patrones de polimorfismo, diferentes a los dos anteriores, para los aislamientos sensibles al medicamento (16). Cuarto, ensayos de PCR y restricción enzimática para detectar resistencia a pirimetamina y sulfadoxina. La pirimetamina se une e inhibe a la dihidrofolato reductasa (DHFR) mientras que la 
sulfadoxina actúa sobre la dihidropteroato sintetasa (DHPS); su combinación, conocida con el nombre de Falcidar $\AA$, produce un efecto sinérgico contra $P$. falciparum que se traduce en la inhibición de la síntesis purínica (17). La resistencia in vitro a la pirimetamina es debida a mutaciones en DHFR que alteran el sitio activo de la enzima; las mutaciones $\operatorname{Ser}^{108}$ a Asn ${ }^{108}$ y Ser $^{108}$ a Thr ${ }^{108}$ están asociadas específicamente con la pérdida de sensibilidad a la pirimetamina y al cicloguanil respectivamente, las mutaciones $\mathrm{Asn}^{51}$ a $\mathrm{Ile}^{51}$ y $\mathrm{Cys}^{59}$ a $\mathrm{Arg}^{59}$ están relacionadas con diferentes niveles de resistencia a la pirimetamina y la mutación Ile ${ }^{164}$ a Leu ${ }^{164}$ confiere resistencia a los dos medicamentos cuando se suma a $\mathrm{Asn}^{108}$ y $\operatorname{Arg}^{59}$ (18-20). Recientemente se describió una nueva mutación (Cys ${ }^{50}$ a $\mathrm{Arg}^{50}$ ) y un inserto de $15 \mathrm{pb}$ entre las posiciones 30 y 31 de DHFR (Bolivia repeat), los cuales se encuentran en alta proporción en aislamientos bolivianos (21). También, sobre el gen que codifica para DHPS se han encontrado algunas diferencias puntuales entre parásitos resistentes y parásitos sensibles, las cuales pueden estar involucradas en la resistencia de $P$. falciparum a sulfadoxina; las mutaciones hasta ahora descritas son: $\mathrm{Ser}^{436}$ a Phe ${ }^{436}$ o Ala ${ }^{436}$, Ala ${ }^{613}$ a Thr ${ }^{613}$ o Ser ${ }^{613}$, Ala $^{437}$ a Gly ${ }^{437}$, Ala ${ }^{581}$ a Gly ${ }^{581}$ y Lys $^{540}$ a Glu ${ }^{540}(21-$ 23).

En este estudio se estableció que el PCR es el ensayo más adecuado para hacer una búsqueda de resistencia in vitro de $P$. falciparum a pirimetamina y sulfadoxina, y que la prueba radiométrica modificada es la mejor alternativa para detectar resistencia in vitro a cloroquina, amodiaquina, mefloquina, quinina y halofantrina.

\section{Materiales y métodos}

\section{Prueba radiométrica}

Parásitos. Las cepas FCB1, FCB2 (Colombia), $7 \mathrm{G} 8$ (Brasil), T4 (Tailandia), Camboya (Camboya), FCR3 (Gambia) y Palo Alto (Uganda), fueron mantenidas en cultivo por medio del método de Trager y Jensen (24) utilizando sangre humana tipo $\mathrm{O} \mathrm{Rh}$. La sangre fue suspendida al $5 \%$ en medio de cultivo RPMI-1640 suplementado con HEPES (25mM), $\mathrm{NaHCO}_{3}(32 \mathrm{mM}), \mathrm{GSH}$ (1mg/l) y suero humano inactivado $(10 \%)$. La sincronización del cultivo se hizo por lisis diferencial con sorbitol 5\% (25) y antes de ser usados en el ensayo radiométrico, los parásitos fueron sometidos a dos lavados con buffer isotónico (HBS). La aplicación de la prueba sobre muestras de $P$. falciparum recolectadas de pacientes, fue descrita previamente por nosotros (7).

Eritrocitos. La sangre fue centrifugada a $2.500 \mathrm{rpm}$ durante $5 \mathrm{~min}$; se retiró el plasma y se lavó tres veces con HBS.

Medicamentos. Los medicamentos usados fueron cloroquina y quinina disueltas en HBS, amodiaquina y mefloquina disueltas en agua destilada, halofantrina (donada porTecnoquímicas S.A.) disuelta en etanol $70 \%$, sulfadoxina (donada por Roche S.A.) disuelta en dimetil sulfóxido y pirimetamina disuelta en ácido láctico $5 \%$.

Preparación del ensayo. Microplacas de 96 pozos fueron dosificadas por duplicado con cloroquina (0; 0,$0114 ; 0,1 ; 0,2 ; 0,4 ; 0,8 ; 1,6 \mu \mathrm{M})$, amodiaquina $(0 ; 0,004 ; 0,015 ; 0,05 ; 0,1 ; 0,25 ; 0,4$ $\mu \mathrm{M})$, mefloquina $(0 ; 0,032 ; 0,064 ; 0,15 ; 0,25 ; 0.4$ $\mu \mathrm{M})$, quinina $(0 ; 0,05 ; 0,15 ; 0,3 ; 0,5 ; 0,8 ; 1,6 \mu \mathrm{M})$, halofantrina $(0 ; 0,001 ; 0,004 ; 0,015 ; 0,03 ; 0,06$ $\mu \mathrm{M})$ y la combinación pirimetamina-sulfadoxina (0-0; 0,002-0,16; 0,008-0,64; 0,0163-1,3; 0,065 $\mu \mathrm{M}-5,2 \mu \mathrm{M})$. El medio fue adicionado hasta un volumen final de $150 \mu \mathrm{l}$ por pozo y la parasitemia $y$ el hematocrito fueron ajustados en $1 \%$; en los pozos con pirimetamina-sulfadoxina se usó RPMI con bajas concentraciones de ácido p-amino benzoico $(10 \mu \mathrm{g} / \mathrm{l})$ y ácido fólico $(0,5 \mu \mathrm{g} / \mathrm{l})$, los cuales interfieren con la acción de estos medicamentos. Las microplacas fueron incubadas a $37{ }^{\circ} \mathrm{C}$ y cuando los parásitos alcanzaron las 32 horas de desarrollo se agregó $0.09 \mu \mathrm{Ci}$ de $\mathrm{H}^{3}$-hipoxantina a cada pozo; finalmente, las microplacas fueron incubadas 18 horas más, antes de procesar las muestras y llevarlas al contador de centelleo (7). Los resultados fueron expresados como $\mathrm{IC}_{50}$, el cual fue definido como la concentración del medicamento que disminuyó la incorporación de $\mathrm{H}^{3}$-hipoxantina en un $50 \%$ (entre la 32 y 44 horas de desarrollo se producen los picos máximos de síntesis de ácidos nucleicos en el parásito y tiene 
lugar la incorporación de la hipoxantina que es precursor de purinas y pirimidinas (26); se adoptaron como umbrales de resistencia los valores de $\mathrm{IC}_{50}$ reportados por la Organización Mundial de la Salud (OMS): 0,0114 $\mu \mathrm{M}$ para cloroquina, 0,004 $\mu \mathrm{M}$ para amodiaquina, $0.5 \mu \mathrm{M}$ para quinina, 0,064 $\mu \mathrm{M}$ para mefloquina, 0,004 $\mu \mathrm{M}$ para halofantrina, $0,016 \mu \mathrm{M}$ para pirimetamina y $1,3 \mu \mathrm{M}$ para sulfadoxina (27). Fue caracterizado como resistente, cualquier aislamiento cuyo $\mathrm{IC}_{50}$ fuera igual o mayor que los valores citados arriba.

\section{Rapid test}

El método usado fue el descrito por IY Gluzman et al. (8) con algunas modificaciones. $150 \mu \mathrm{l}$ de muestra fueron incubados a $37^{\circ} \mathrm{C}$ con $\mathrm{H}^{3}$-cloroquina (donada por el Dr. D. Krogstad de la Universidad de Tulane, New Orleans, Louissiana, EUA) en presencia y ausencia de verapamil; una hora después, el precipitado de células rojas fue aislado de la $\mathrm{H}^{3}$-cloroquina extracelular por centrifugación a través de un colchón de aceite. Al precipitado se adicionaron $75 \mu \mathrm{l}$ de protosol:etanol (1:2), $25 \mu \mathrm{lde} \mathrm{H}_{2} \mathrm{O}_{2}(30 \%)$ y $25 \mu \mathrm{l}$ de $\mathrm{HCl}(1 \mathrm{~N})$; finalmente, se agregó el coctel de centelleo y las muestras fueron llevadas al contador. Debido a que el protosol ha sido declarado tóxico y no está disponible comercialmente, se ensayaron varios compuestos como saponina, tolueno, ácido tricloro acético (TCA) y $\mathrm{HCl} 1 \mathrm{~N}$ para reemplazarlo en la prueba. Una vez definido el protocolo, el ensayo fue aplicado sobre varias cepas de $P$. falciparum cultivadas in vitro (FCB1, FCB2, 7G8, T4, Palo Alto y Camboya) y sobre aislamientos recolectados en el campo, donados por el Dr. D. Krogstad (OK1, OK2, OK3 de Mali-Africa y JAV y JAJ de Buenaventura, Colombia). Los resultados fueron expresados como porcentajes de cambio, donde los clones puros de laboratorio que son sensibles a cloroquina (CQ-S) deben tener porcentajes entre $-10 \%$ y $-15 \%$ y los clones puros resistentes a cloroquina (CQ-R) entre $+20 \%$ y $+60 \%$; los resultados entre $-10 \%$ y $+20 \%$ pueden ser producidos por aislamientos con mezclas de parásitos CQ-S y CQ-R. Las cepas Indochina I/CDC (CQ-R) y Haiti135 (CQ-S) fueron usadas como controles.

\section{Ensayos de PCR y digestión enzimática}

Obtención del ADN. El ADN fue extraido de las cepas de laboratorio FCB1, FCB2, FCR3, T4, $7 \mathrm{G} 8$, Camboya y Palo Alto cultivadas in vitro, del aislamiento OK2 recolectado sobre papel de filtro y de muestras aplicadas sobre papel de filtro de las cepas de laboratorio Haiti135, Indochina I/CDC (donadas por el Dr. D. Krogstad), Dd2, V1/S y 3D7 (donadas por el Dr. C. Plowe de la Universidad de Maryland, Baltimore, Maryland, EUA). Se obtuvo ADN de aislamientos y plásmidos usados como controles positivos y/o negativos para algunas mutaciones en DHFR y DHPS: un plásmido con $\mathrm{Arg}^{50}$, uno con la secuencia Bolivia repeat y otro con la secuencia silvestre de DHFR, una cepa originaria de Uganda con $\mathrm{Ala}^{581}$, el aislamiento "18" con Gly ${ }^{581}$, el aislamiento "FF74" como control positivo para corte con la enzima de restricción MspA1I (mutación 436) y negativo para cortes con Fokl (mutación 540) y Avall (mutación 437), el aislamiento "B3" como control negativo para corte con MspA1l y positivo para corte con Fokl, y el aislamiento "FF75" como control positivo para corte con Avall.

Extracción de ADN de cultivos in vitro. Cultivos de $P$. falciparum con parasitemias de aproximadamente $10 \%$ se centrifugaron a $800 \mathrm{~g}$ durante $5 \mathrm{~min}$; cada precipitado se resuspendió en 10 volúmenes de saponina $0,15 \%$ disuelta en HBS y se incubó por $10 \mathrm{~min}$ a temperatura ambiente. Los parásitos se recuperaron por centrifugación a $15.000 \mathrm{~g}$ durante $10 \mathrm{~min}$ a $4{ }^{\circ} \mathrm{C}$; el precipitado se lavó dos veces con HBS y se resuspendió en 3 volúmenes de buffer de lisis (proteinasa $\mathrm{K} 0,2 \mathrm{mg} / \mathrm{ml}$, SDS $0,5 \%$, EDTA pH $8,025 \mathrm{mM}$, Tris- $\mathrm{HCl} \mathrm{pH} 8,010 \mathrm{mM}$ y $\mathrm{NaCl} 0,1 \mathrm{mM}$ ) y se incubó durante 18 horas a $50^{\circ} \mathrm{C}$. El lisado fue sometido a dos extracciones fenólicas muy suaves seguidas por una extracción fenol: cloroformo (1:1); finalmente se dializó contra 4 litros de TE durante 48 horas.

Extracción de ADN de muestras recolectadas sobre filtros. Las muestras, recolectadas sobre papel Whatman $3 \mathrm{MM}$, fueron colocadas en $1 \mathrm{ml}$ de saponina $0,5 \%$ disuelta en buffer fosfato salino (PBS) e incubadas toda la noche a $4{ }^{\circ} \mathrm{C}$. La solución café fue aspirada y reemplazada con 1 $\mathrm{ml}$ de PBS antes de incubar por $30 \mathrm{~min}$ a $4{ }^{\circ} \mathrm{C}$; 
finalmente, se descartó el PBS y se agregaron $200 \mu \mathrm{l}$ de una solución de Chelex-100 (5\%), incubando a $100^{\circ} \mathrm{C}$ durante $10 \mathrm{~min}$ con constante agitación. Tras centrifugación a 10.000 g por 2 min, el sobrenadante fue recuperado, centrifugado de nuevo bajo las mismas condiciones y recolectado en un tubo nuevo. Los sobrenadantes fueron usados para hacer los ensayos de PCR (28).

PCR para detectar resistencia a cloroquina. El PCR para detectar el polimorfismo de pfmdr1 se hizo usando $A D N$ de cinco aislamientos de campo (OK1, OK2, OK3, JAV y JAJ) y de las cepas de laboratorio FCB1, FCB2, FCR3, 7G8, T4, Palo Alto y Camboya. En este ensayo, las condiciones ajustadas fueron $\mathrm{MgCl}_{2} 4.0 \mathrm{mM}$, iniciadores (primers) $1 \mu \mathrm{M}$ y 2,5 unidades de TAQ polimerasa.

PCR y restricción enzimática para detectar mutaciones en la dihidratofolatporeductasa (DHFR) asociadas con resistencia a pirimetamina. Se hizo una primera reacción para amplificar el gen de DHFR y luego se hizo un nested-PCR que mejoró tanto la sensibilidad en las muestras con baja parasitemia (falsos negativos), como la especificidad en las muestras con alta parasitemia (falsos positivos). Para la mutación 108, por ejemplo, los primers fueron diseñados para detectar cada una de las tres posibles bases en esa posición, esos primers diagnósticos diferían en una única base en el extremo 3' y fueron usados con un primercomún ubicado en una zona conservada del gen (figura 1). La misma estrategia fue usada para detectar mutaciones en las posiciones 51,59 y $164(29,30)$; para las reacciones se usó $\mathrm{MgCl}_{2} 1,5 \mathrm{mM}$ y $1 \mu \mathrm{M}$ de primers. La mutación en la posición 50 fue detectada por digestión con la enzima de restricción Tail, cuya secuencia de corte coincide con la secuencia del mutante; la digestión se hizo a partir de un producto de amplificación del gen DHFR obtenido por PCR. Para detectar la secuencia Bolivia repeat, se usó el producto obtenido en el PCR para la mutación Cys ${ }^{59}$ a $\mathrm{Arg}^{59}$; dos plásmidos, uno con el gen DHFR más el inserto y otro con el gen DHFR silvestre, fueron usados en una electroforesis donde la presencia de Bolivia repeat se estableció con base en la migración de los productos en el gel (21).

PCR y restricción enzimática para detectar mutaciones en la dihidropteoratosintetasa (DHPS)

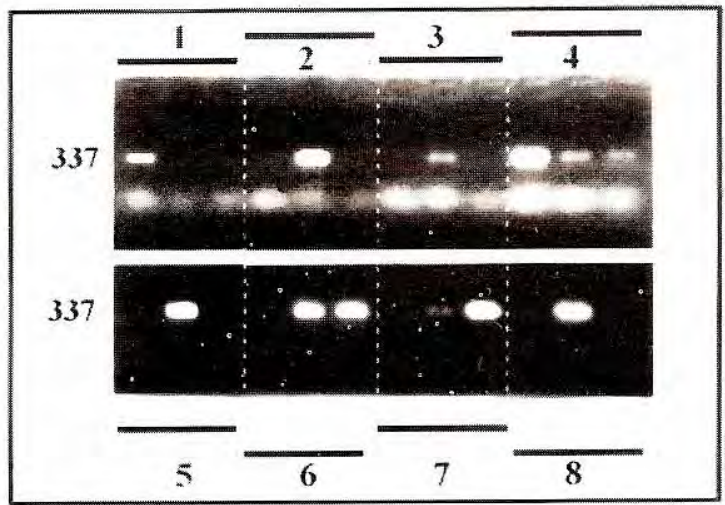

A

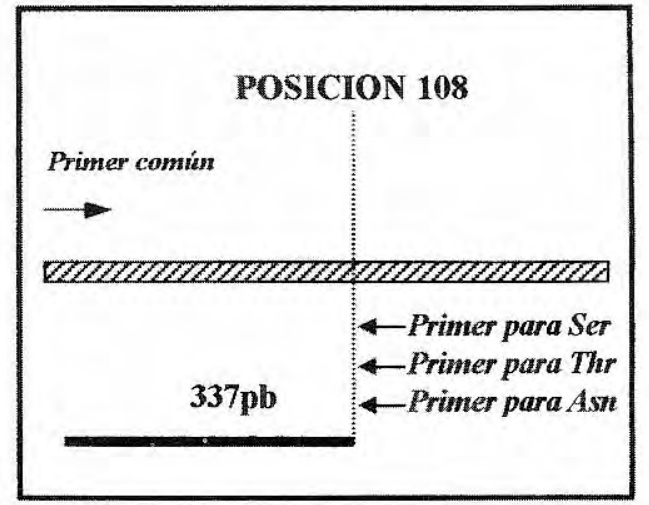

B

Figura 1. Estrategia utilizada para detectar mutaciones en la dihidrofolato reductasa. (A) Detección de las mutaciones en la posición 108 del gen DHFR; gel de agarosa 1.5\% teñido con bromuro de etidio. En cada bloque las líneas primera, segunda y tercera corresponden a Ser, Thr y Asn respectivamente, excepto en el bloque 8 donde el orden es Ser Asn y Thr. Un bloque con más de una señal indica la presencia de un aislamiento con infección mixta. Bloque 1: Haiti135, bloque 2: FCB2, bloque 3: Palo Alto, bloque 4: controles positivos (3D7, FCR3,V1/S), bloque 5: FCB1, bloque 6: Camboya, bloque 7: OK1, bloque 8: 7G8. (B) La barra $(/ / / / / / /)$ representa el gen de la Dihidrofolato reductasa (DHFR), la línea engrosada corresponde al producto de PCR esperado, la dirección de las flechas indica el sentido de los "primers" (en cursiva) y la línea punteada indica la posición 108. 


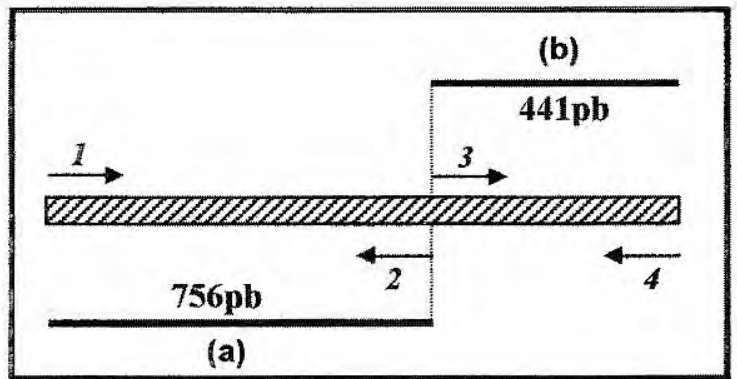

A

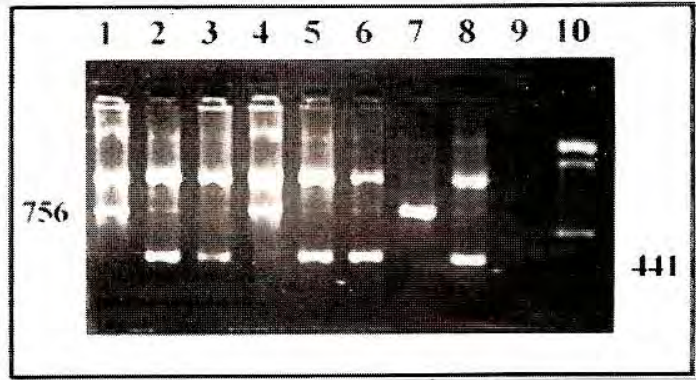

B

Figura 2. Estrategia utilizada para detectar mutaciones en la dihidropteroato sintetasa. (DHPS). (A) La barra ( $/ / / / / / /$ ) representa el gen de la dihidropteroato sintetasa (DHPS), la dirección de las flechas indica el sentido de los "primers" (1,2,3 y 4) y la línea punteada indica la posición 581. Las líneas engrosadas corresponden a los productos de PCR esperados, (a) para aislamientos resistentes y (b) para aislamientos sensibles. (B) Gel de agarosa $2 \%$ teñido con bromuro de etidio donde se observan los productos obtenidos para varios aislamientos. Línea 1:T4; línea 2: Camboya; línea 3: FCR3; línea 4: 7G8; línea 5: Palo Alto; línea 6: OK2; línea 7: Control positivo para el tipo mutante; línea 8: control positivo para el tipo silvestre; línea 9: control negativo ( $\sin$ ADN); línea 10: Lader 100. Las líneas 1 y 4 corresponden a aislamientos con el tipo mutante y las líneas 2, 3, 5 y 6 corresponden a aislamientos con el tipo silvestre.

asociadas con resistencia a sulfadoxina. Se hizo una primera reacción para amplificar el gen de DHPS y luego se hizo un nested-PCR en el que se utilizó simultáneamente dos parejas de primers que amplifican productos diferentes, uno asociado al tipo silvestre y el otro al tipo mutante; de este modo, los aislamientos se identifican fácilmente por el tamaño de los productos amplificados (figura 2). En las reacciones se usó $\mathrm{MgCl}_{2} 2,5 \mathrm{mM}$ y $1 \mu \mathrm{M}$ de primers. Las mutaciones Lys $^{540}$ a Glu ${ }^{540}$ Ser $^{436}$ a Ala ${ }^{436}$ y Ala $^{437}$ a Gly ${ }^{437}$ fueron detectadas por medio de digestión con las enzimas de restricción Fokl, MspA1l y Avall respectivamente $(21,31)$.

\section{Resultados y discusión}

\section{Prueba radiométrica}

En este ensayo, todas las cepas fueron resistentes a cloroquina, amodiaquina $y$ mefloquina; Camboya, FCB2, FCR3 y Palo Alto, a quinina; Camboya y FCR3, a halofantrina, y T4 y $7 \mathrm{G} 8$, a la combinación pirimetamina-sulfadoxina (cuadro 1).

La prueba radiométrica fue eficaz para determinar de manera simultánea la resistencia de $P$. falciparum a varios medicamentos y puede ser aplicada sin dificultad alguna sobre cualquier cepa
Cuadro 1. Comportamiento de cepas de Plasmodium falciparum en la prueba radiométrica. Las casillas sombreadas corresponden a aislamientos resistentes y las no sombreadas a aislamientos sensibles, las cepas aparecen debajo de cada medicamento en orden descendente de resistencia (para quinina por ejemplo, la cepa FCR3 es la más resistente y FCB1 la más sensible). $C Q$, cloroquina; $A Q$, amodiaquina; $M Q$, mefloquina; $Q$, quinina; $H$, halofantrina; $P-S$ pirimetamina-sulfadoxina.

\begin{tabular}{|c|c|c|c|c|c|}
\hline \multicolumn{7}{|c|}{ MEDICAMENTO } \\
\hline & AQ & CQ & Q & H & P-S \\
\hline Palo Alto & $7 G 8$ & FCR3 & FCR3 & FCR3 & 7G8 \\
\hline Camboya & Palo Alto & Palo Alto & Palo Alto & Camboya & T4 \\
\hline 7G8 & FCR3 & FCB2 & FCB2 & T4 & Camboya \\
\hline T4 & Camboya & T4 & 7G8 & 7G8 & Palo Alto \\
\hline FCB2 & FCB2 & FCB1 & Camboya & Palo Alto & FCB2 \\
\hline FCB1 & FCB1 & 7G8 & T4 & FCB1 & FCR3 \\
\hline FCR3 & T4 & Camboya & FCB1 & FCB2 & FCB1 \\
\hline
\end{tabular}

de referencia. El ensayo tiene varias ventajas como la posibilidad de hacer una determinación cuantitativa de la resistencia a varios medicamentos, la corta duración si es comparado con la prueba in vivo, la rapidez con que puede analizarse un gran número de muestras en un corto tiempo, la reproducibilidad de los resultados 
y la sencillez técnica del método. Uno de los más grandes obstáculos del radioensayo es que no se puede aplicar sobre muestras de pacientes que han recibido antimaláricos en las semanas previas al estudio y, por lo general, en las zonas endémicas la automedicación es frecuente. Otro inconveniente radica en la dificultad ya reportada que representa adaptar los aislamientos a condiciones de cultivo in vitro (7).

\section{Rapid test}

$\mathrm{El} \mathrm{HCl} \mathrm{fue} \mathrm{elegido} \mathrm{como} \mathrm{la} \mathrm{mejor} \mathrm{alternativa} \mathrm{para}$ reemplazar la mezcla protosol:etanol, no solo porque produjo los resultados más cercanos a los obtenidos con el protocolo original, sino también por ser el compuesto más económico y seguro entre los usados. La saponina no fue alternativa adecuada debido a que forma espuma que aumenta el riesgo de contaminación radioactiva.

En el cuadro 2 aparecen los porcentajes de cambio obtenidos en varios experimentos (los rangos de resistencia y sensibilidad son muy

Cuadro 2. Comportamiento de aislamientos de Plasmodium falciparum en el Rapid test. Los clones puros sensibles a Cloroquina (CQ-S) deben tener porcentajes de cambio entre $-10 \%$ y $-15 \%$ y los clones puros resistentes a cloroquina (CQ-R) entre $+20 \%$ y $+60 \%$. Resultados entre $-10 \%$ y $+20 \%$ pueden ser producidos por aislamientos con mezclas de parásitos $C Q-S$ y CQ-R. EXP $\mathbf{1}$ al $\mathbf{5}$, corresponden a cinco experimentos diferentes llevados a cabo de manera consecutiva, las casillas sombreadas corresponden a aislamientos resistentes.

\begin{tabular}{|l|c|c|c|c|c|}
\hline & \multicolumn{5}{|c|}{ PORCENTAJES DE CAMBIO } \\
\hline MUESTRA & EXP.1 & EXP.2 & EXP.3 & EXP.4 & EXP.5 \\
\hline FCB1 & & & +24 & +20 & +23 \\
\hline FCB2 & & +40 & & & \\
\hline CAMBOYA & & & +3.0 & +10 & +20 \\
\hline T4 & & & +28 & +27 & +23 \\
\hline 7G8 & & & +15 & +17 & +16 \\
\hline PALO ALTO & & & +34 & +23 & \\
\hline HAIT1 135 & -11 & -5 & -8.7 & -14.7 & -12.9 \\
\hline INDOCHINA & +23 & +37 & +24 & +31 & +12.4 \\
\hline JAJ & +22.5 & & & & \\
\hline JAV & +3.5 & & & & \\
\hline OK1 & -1 & -2 & -3 & & \\
\hline OK2 & -3 & -8 & -12 & & \\
\hline OK3 & -6 & -8 & -8 & & \\
\hline
\end{tabular}

amplios y no es conveniente presentar promedios de los resultados) para las cepas de laboratorio y aislamientos de campo usados. El rango de sensibilidad está definido entre $-10 \%$ y $-15 \%$, pero Haití135 (cepa referencia CQ-S) tuvo porcentajes de cambio entre $-5 \%$ y $-17,7 \%$; de igual forma, el rango de resistencia está definido entre $+20 \%$ $y+60 \%$ e Indochina $/ / C D C$ (cepa referencia CQ-R) tuvo porcentajes de cambio entre $+12,4 \%$ y $+37 \%$. Lo que parece sugerir estos resultados es que es difícil aplicar un razonamiento válido a nuevos aislamientos usando estos rangos; por ejemplo, si en un ensayo los porcentajes de cambio para dos aislamientos son $-5 \% \mathrm{y}+12,4 \%$, eso indicaría que en esas muestras hay más de una población de P. falciparum (8); sin embargo, como ya se mostró, esos datos se obtuvieron para Haiti135 e Indochina I/CDC, las cuales son cepas referencia para $C Q-S$ y $C Q-R$.

Las cepas Camboya y 7G8 exhibieron porcentajes de cambio típicos de aislamientos con infección mixta, pero los resultados para la primera fueron aumentando paulatinamente hasta alcanzar valores característicos de una cepa CQ-R. Para tratar de comprobar la posible coexistencia de diferentes poblaciones, se hizo un PCR para detectar el polimorfismo del bloque 2 del gen que codifica para la proteína de superficie del merozoito (MSP-1), el cual está dividido en 17 bloques caracterizados como conservados, semiconservados o variables. El bloque 2 es variable y dentro de él se han encontrado 3 formas polimórficas denominadas $\mathrm{K} 1, \mathrm{MAD} 20$ y $\mathrm{RO} 33$ $(32,33)$; se espera que para una cepa pura de laboratorio sólo aparezca producto de amplificación para uno de estos tres alotipos. Para las cepas Camboya y 7G8, hubo amplificación para dos (K1, MAD20) y tres alotipos (K1, MAD20 y $\mathrm{RO} 33$ ) respectivamente, mientras que para las cepas Haiti135, FCB-1, FCB2, e Indochinal/CDC solo hubo amplificación para un alotipo (K1 para la primera y MAD-20 para las tres restantes); esto confirmó la coexistencia de al menos dos poblaciones en Camboya y almenos tres en 7G8 (datos no mostrados).

Los resultados obtenidos al usar el Rapid-test y el ensayo radiométrico concordaron para las cepas FCB1, FCB2, T4 y Palo Alto (CQ-R en los 
dos ensayos, cuadros 1 y 2); las cepas Camboya y $7 \mathrm{G} 8$ fueron caracterizadas en el ensayo radiométrico como resistentes a cloroquina (cuadro 1), pero en el Rapid-test produjeron porcentajes de cambio fuera del rango de CQ-R (cuadro 2). Es posible que los resultados obtenidos en el Rapid-test hayan sido producidos por la coexistencia de diferentes poblaciones de parásitos en estas dos cepas, mientras que el comportamiento en la prueba radiométrica puede obedecer a que fueron seleccionadas poblaciones de parásitos CQ-R durante el largo período de cultivo al que fueron sometidas todas las cepas antes de adelantar el ensayo (34).

El Rapid-test determina en 2 o 3 horas la resistencia a cloroquina, permite usar aislamientos con parasitemias tan bajas como $0,01 \%$ (datos no mostrados), no precisa usar diluciones seriadas de cloroquina, no necesita que los parásitos se desarrollen en condiciones de cultivo in vitro y los resultados del ensayo no se alteran si las muestras provienen de pacientes previamente tratados con cloroquina. La debilidad de la técnica radica no sólo en el alto costo de la $\mathrm{H}^{3}$-cloroquina, sino también en que las cepas de referencia para $C Q-R$ y $C Q-S$ no siempre se ajustan a los rangos definidos en el Rapid-test para resistencia y sensibilidad a cloroquina; adicionalmente, es importante observar que hay versiones encontradas con respecto a la utilidad de este ensayo como prueba diagnóstica de resistencia a escala epidemiológica. En un estudio en el que se comparó el comportamiento de aislamientos analizados de manera simultanea en la prueba in vivo, en dos ensayos isotópicos y en el Rapid-test, se encontró una alta concordancia entre los resultados de los dos métodos isotópicos, una moderada correlación entre los resultados de estos dos ensayos y la prueba in vivo (discrepancia posiblemente ocasionada por factores como la respuesta inmune y la variación farmacocinética, los cuales son eliminados en los ensayos in vitro) y una pobre relación entre los resultados del Rapid-test y los otros ensayos (35). Este último resultado difiere de otros obtenidos previamente en Africa, donde el Rapid-test ha sido y sigue siendo ampliamente usado como prueba diagnóstica de resistencia a cloroquina; en estos estudios se ha encontrado una muy buena correlación entre los resultados del Rapid-test, los ensayos isotópicos y las pruebas in vivo (36).

Aunque el Rapid-testha sido una alternativa eficaz para detectar resistencia a cloroquina en zonas endémicas donde este medicamento es el tratamiento quimioterapéutico de primera línea (36), es también importante considerar las dificultades detectadas por nosotros y la pobre correlación que algunos autores han establecido entre los resultados del Rapid-testy otros ensayos (35). Estos datos nos permiten sugerir que la técnica debe ser sometida a mayor estudio antes de determinar su aplicabilidad como prueba diagnóstica de CQ-R a escala epidemiológica.

\section{Ensayos con PCR}

PCR para detectar resistencia a cloroquina. Con el ánimo de observar el polimorfismo de los aislamientos de campo, se extrajo el ADN de muestras de campo recolectadas en papel filtro y se usaron $4 \mu \mathrm{l}$ de cada extracción en las pruebas de PCR; no hubo señal alguna tras electroforesis. Para descartar la posibilidad de que hubiera habido una falla en la obtención de $A D N$, se

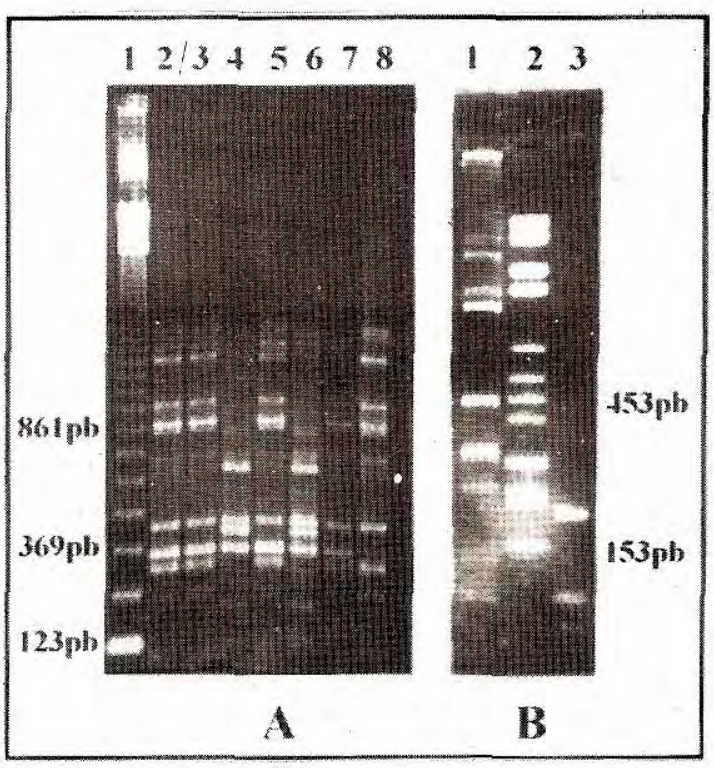

Figura 3. Análisis del Polimorfismo 3' de PfMDR1. Gel de agarosa $2 \%$ teñido con bromuro de etidio donde aparecen los productos de amplificación del gen Pfmdr1. (A). Línea 1: Lader 123; líneas 2 y 3:FCB1; línea 4: 7G8; línea 5: Camboya; línea 6: T4; línea 7: FCR3; línea 8: Palo Alto. (B). Línea 1: Palo alto; línea 2: Marker VI; línea 3: FCB2. 
usaron $4 \mu \mathrm{l}$ de cada extracción para detectar alotipos del gen que codifica para MSP-1 $(32,33)$; la aparición de productos de amplificación para todas las muestras (datos no mostrados) indicó que la extracción de ADN había sido eficiente y que los ensayos de PCR para detectar resistencia a cloroquina no eran aplicables a aislamientos recolectados en campo. El ensayo se aplicó también sobre cepas de laboratorio y en la figura 3 puede verse el patrón observado para FCB1, FCB2, 7G8, T4, Camboya, FCR3 y Palo Alto. Se encontraron cuatro tipos de polimorfismo: polimorfismo tipo 1 (FCB1, Camboya y FCR3), semejante al descrito como tipo K1; polimorfismo tipo 2 (T4 y 7G8), semejante al descrito como tipo 7G8; Polimorfismos tipo 3 (Palo Alto), y tipo 4 (FCB2), no descritos anteriormente. Habiendo caracterizado ya estas cepas como CQ-R por medio de la prueba radiométrica y el Rapid-test, es evidente que existen más de dos patrones asociados con resistencia a cloroquina y que, de no haber sido por esos ensayos previos, no hubiera sido posible asignar carácter resistente o sensible a los nuevos tipos de polimorfismo observados.

Cuadro 3. Mutaciones en la dihidrofolato reductasa (DHFR) detectadas por PCR o restricción enzimática. Las columnas sombreadas corresponden a los genotipos asociados con resistencia a Pirimetamina. ND $=$ Dato no disponible.

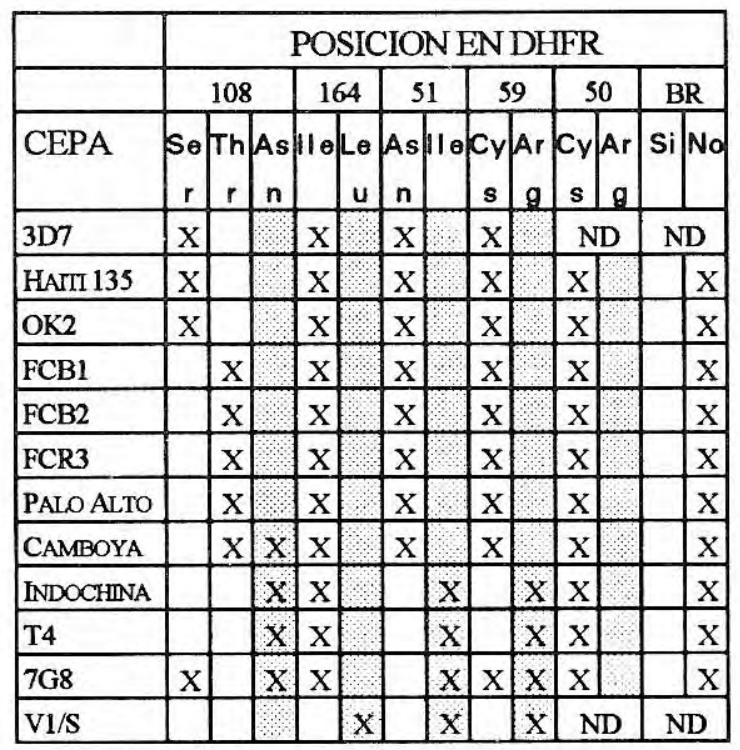

Concluimos que no hay relación alguna entre el polimorfismo de los productos de PCR en la región 3' no codante del gen pfmdr1 y la resistencia a cloroquina.

PCR para detectar resistencia in vitro a pirimetamina y sulfadoxina. El análisis de las mutaciones en el gen DHFR que confieren resistencia a pirimetamina aparece en el cuadro 3. Haití 135, 3D7 y OK2 fueron los únicos aislamientos con tipo silvestre para todas las posiciones de DHFR analizadas; FCB1, FCB2, FCR3, Palo Alto y Camboya exhibieron el genotipo $\mathrm{Thr}^{108}$ asociado con resistencia a cicloguanil. Al igual que en el radioensayo y el Rapid-test, Camboya resultó ser una mezcla de al menos dos poblaciones de $P$. falciparum, una de ellas con resistencia a pirimetamina $\left(A s n^{108}\right)$ y otra con resistencia a cicloguanil $\left(\mathrm{Thr}^{108}\right.$ ) (cuadro 3 y figura 1 (A), bloque 6). La cepa $7 \mathrm{G} 8$ resultó ser también una cepa mezclada (cuadro 3 y figura 1 (A), bloque 8) y sumó junto con Indochina I/CDC, T4 y $\mathrm{V} 1 / \mathrm{S}$, el mayor número de mutaciones que confieren resistencia a pirimetamina.

Aún no es muy clara la relación que hay entre las mutaciones en DHFR y DHPS, es decir, que aún no hay acuerdo respecto a la importancia que cada mutación tiene en el momento de determinar la respuesta in vivo a Falcidar@ $(37,38)$. Algunas hipótesis sugieren que la respuesta in vivo está determinada por la resistencia a pirimetamina, otras afirman que la resistencia a sulfadoxina define la respuesta a Falcidar $($ y, finalmente, algunas sugieren que es necesaria una acción concertada. La cepa Camboya exhibió un genotipo $\mathrm{Asn}^{108}$, Thr ${ }^{108}$ (asociados con resistencia a pirimetamina y cicloguanil, respectivamente) y, sin embargo, en la prueba radiométrica fue clasificada como sensible a pirimetaminasulfadoxina. Aunque es difícil hacer conclusiones respecto a una cepa mezclada, la explicación puede radicar en que el aislamiento no presentó ninguna mutación en DHPS, es decir que no tenía alguno de los genotipos hasta ahora asociados con resistencia a sulfadoxina. Como lo que se evalúa en el ensayo radiométrico es la resistencia a la mezcla pirimetamina-sulfadoxina, esto parece indicar que las mutaciones en DHPS también son importantes en el momento de hablar de 
Cuadro 4. Mutaciones en la dihidropteroato sintetasa (DHPS)detectadas por PCR o restricción enzimática. Las columnas sombreadas corresponden a los genotipos mutantes, posiblemente asociados con resistencia a sulfadoxina.

\begin{tabular}{|c|c|c|c|c|c|c|c|c|c|c|c|c|}
\hline & \multicolumn{12}{|c|}{ POSICION EN DHPS } \\
\hline & \multicolumn{3}{|c|}{436} & \multicolumn{2}{|c|}{437} & \multicolumn{2}{|c|}{540} & \multicolumn{2}{|c|}{581} & \multicolumn{3}{|c|}{613} \\
\hline CEPA & Se & $\mathrm{Ph}$ & Al & AI & G) & $-y$ & G) & Al & GI & AI & Se & $T h$ \\
\hline & $\mathbf{r}$ & $\theta$ & a & a & $y$ & $\mathbf{s}$ & $\mathbf{u}$ & a & $y$ & a & $r$ & $r$ \\
\hline HAITT 135 & & & & $\mathrm{X}$ & & $X$ & & $\mathrm{X}$ & & $\mathrm{X}$ & & \\
\hline OK2 & & & & $\mathrm{x}$ & & $\mathrm{x}$ & & $\mathrm{x}$ & & $\mathrm{x}$ & & \\
\hline FCB1 & & & & $\mathrm{X}$ & & $\mathrm{X}$ & & $\mathrm{X}$ & & $\mathrm{x}$ & & \\
\hline FCB2 & & & & $\mathrm{X}$ & & $\mathrm{X}$ & & $\mathrm{x}$ & & $\mathrm{x}$ & & \\
\hline FCR3 & & & & $\mathrm{X}$ & & $\mathrm{x}$ & & $\mathrm{X}$ & & $\mathrm{X}$ & & \\
\hline PALO ALTO & & & & $\mathrm{X}$ & & $\mathrm{X}$ & & $\mathrm{X}$ & & $\mathrm{x}$ & & \\
\hline CAMBOYA & & & & $\mathrm{X}$ & & $\mathrm{X}$ & & $\mathrm{x}$ & & $\mathrm{X}$ & & \\
\hline INDOCHINA & $\mathrm{x}$ & & $\mathrm{x}$ & & $\mathrm{X}$ & $\mathrm{X}$ & & $\mathrm{X}$ & & $\mathrm{x}$ & & \\
\hline $\mathrm{T} 4$ & $\mathrm{x}$ & & & & $x$ & $\mathrm{X}$ & & & $x$ & $x$ & & \\
\hline 7G8 & $\mathrm{x}$ & & & & $x$ & $X$ & & & $\mathrm{X}$ & $\mathrm{x}$ & & \\
\hline
\end{tabular}

resistencia a Falcidar $\circledast$. Los resultados mostraron que las cepas con mutaciones asociadas a resistencia en DHFR y en DHPS (T4 y 7G8, cuadros 3 y 4), fueron las únicas que a su vez exhibieron un comportamiento resistente a la combinación pirimetamina-sulfadoxina en la prueba radiométrica (cuadro 1); esta evidencia permitiría sugerir de manera muy preliminar que tanto mutaciones en DHFR como mutaciones en DHPS juegan un papel en la resistencia a Falcidar®. Es evidente que para el caso particular de este estudio no puede hacerse alguna interpretación concluyente debido al pequeño número de muestras analizadas en los ensayos in vitro y a la carencia de datos de ensayos in vivo.

En resumen, los ensayos de PCR para detectar resistencia a pirimetamina y sulfadoxina son rápidos, sensibles, tienen buena correlación con el ensayo radiométrico y minimizan las restricciones que este último presenta para seleccionar pacientes; es decir que los tratamientos previos con Falcidar $\circledast$ no afectan los resultados y no hay necesidad de manipular material radioactivo o adaptar los aislamientos a condiciones de cultivo in vitro. Además, la colección, transporte y almacenamiento de muestras sobre papel filtro, es un método eficaz que simplifica en gran manera la obtención y manipulación de muestras para los ensayos. Es evidente, sin embargo, que son demasiadas mutaciones las que deben ser analizadas y que un paso prioritario para simplificar la técnica y reducir tiempo y costos, es establecer cuáles mutaciones o cuáles combinaciones de ellas son determinantes para la resistencia in vivo a Falcidar $\circledast$. De manera muy preliminar, los resultados sugieren que la resistencia a Falcidar® está determinada por alteraciones tanto en DHFR como en DHPS.

En conclusión, se estableció que el PCR es el ensayo más adecuado para hacer una búsqueda de resistencia in vitro de $P$. falciparum a pirimetamina y sulfadoxina, que esa búsqueda permite ocasionalmente detectar la existencia de infecciones múltiples, que en algunas ocasiones el Rapid-test produce resultados difícilmente interpretables, que los ensayos de PCR diseñados hasta ahora para establecer resistencia a cloroquina no son confiables y que la prueba radiométrica modificada es, a pesar de los inconvenientes presentados, la mejor alternativa para detectar resistencia in vitro a cloroquina, amodiaquina, mefloquina, quinina y halofantrina.

\section{Agradecimientos}

Este trabajo fue apoyado por el Organismo Internacional de Energía Atómica (OIEA). Agradecemos a Fran Krogstad y a Donald Krogstad por su asistencia en el trabajo con el Rapid-test, a Joe Cortese y a Christopher Plowe por su asistencia en los ensayos para detectar mutaciones en DHFR y DHPS, y a Stella Buitrago por su colaboración en la colección de aislamientos de $P$. falciparum.

\section{Referencias}

1. WHO. The World Health Report. Geneve: World Health Organization; 1997.

2. Wernsdorfer WH. The development and spread of drug resistant malaria. Parasitol. Today 1991;7:297-302.

3. Espinal CA, Cortés GT, Guerra P, Arias E. Sensitivity of Plasmodium falciparum to antimalarial drugs in Colombia. Am JTrop Med Hyg 1986;34:675-80. 
4. Giraldo LE, Acosta MC, Labrada LA, Praba A, Montenegro J, Saravia NG, et al. Frequency of the Asn108 and Thr-108 point mutations in the dihydrofolate reductase gene in Plasmodium falciparum from southwest Colombia. Am JTrop Med Hyg 1998;59:124-8.

5. Cowman AF, Foote J. Chemotherapy and drug resistance in malaria. Int J Parasitol 1990;20:503-13.

6. Rieckmann KH, Campbell GH, Sax LJ, Mrema JE. Drug sensitivity of Plasmodium falciparum. An in vitro microtechnique. Lancet 1978;1:22-3.

7. Chaparro J, Wasserman M. Desarrollo de una prueba radiométrica para la detección de resistencia múltiple a medicamentos de Plasmodium falciparum. Biomédica 1999;19:25-34.

8. Gluzman IY, Krogstad DJ, Orjih AU, Nkangineme K, Wellems TE, Martin JT, et al. A rapid in vitro test for chloroquine-resistant Plasmodium falciparum. Am J Trop Med Hyg 1990;42:521-6.

9. Chaparro J, Rojas MO, Krogstad F, Wasserman LM, Krogstad D. Modification of the rapid-test for chloroquine (CQ) resistance. [Abstract]. Am J Trop Med Hyg 1997;57:280-1.

10. Krogstad DJ, Gluzman IY, Kyle DE, Oduola AM, Martin SK, MilhousWK, et al. Efflux of chloroquine from Plasmodium falciparum: mechanism of chloroquine resistance. Science 1987;238:1283-5.

11. Williams JB. Drug efflux as a mechanism of resistance. Brit J Biomed Sci 1996;53:290-3.

12. Martin SK, Oduola AMJ, Milhous WK. Reversal of chloroquine resistance in Plasmodium falciparum by verapamil. Science 1987;224:994-6.

13. Rubio JP, Cowman AF. The ATP-binding cassette (ABC) gene family of Plasmodium falciparum. Parasitol Today 1996;12:135-40.

14. Chow LM,Volkman SK. Plasmodium and Leishmania: the role of MDR genes in mediating drug resistance. Exp Parasitol 1998;90:135-41.

15. Foote SJ,Thompson JK, Cowman AF, Kemp DJ. Amplification of the multidrug resistance gene in some chloroquine-resistant isolates of $P$. falciparum. Cell 1989;57:921-30.

16. Foote SJ, Kyle DE, Martin RK, Oduola AMJ, Forsyth K, Kemp,D.J, et al. Several alleles of the multigrug resistance gene are closely linked to chloroquine resistance in Plasmodium falciparum. Nature 1990;345:255-8.

17. Gilman GA, Rall TW, Nies AS, Taylor P. The pharmacological basis of therapeutics. Edited by Mc Graw Hill international Editions.). Medical Series. Eighth Edition 1991;1811 Pag.

18. Peterson DS, Walliker D, Wellems TE. Evidence that a point mutation in dihydrofolate reductase-thymidylate synthase confers resistance to pyrimethamine in falciparum Malaria. Proc Natl Acad Sci USA 1988;85:9114-8.
19. Peterson DS, MilhousWK, WellemsTE. Molecular basis of differential resistance to cycloguanil and pyrimethamine in Plasmodium falciparum malaria. Proc Natl Acad Sci USA 1990;87:3018-22.

20. Tanaka M, Gu H, Bzik DJ, Li W, Inselburg JW. Dihydropholate reductase mutations and chromosomal changes associated with pyrimethamine resistance of Plasmodium falciparum. Mol Biochem Parasitol 1990;39:12734.

21. Plowe CV, Cortese JF, Djimde A, Nwanyanwu OC, Watkins WM, Winstanley PA, et al. Mutations in Plasmodium falciparum dihydrofolate reductase and dihydropteroate synthase and epidemiologic patterns of pyrimethamine-sulfadoxine use and resistance. $J$ Infect Dis 1997;176:1590-6.

22. Triglia T, Cowman AF. Primary structure and expression of the dihydropteroate synthase gene of Plasmodium falciparum. Proc Natl Acad Sci USA 1994;85:7149-53.

23. Wang P, Brooks DR, Sims PFG, Hyde JE. A mutationspecific PCR system to detect sequence variation in the dihydropteroate synthetase gene of Plasmodium falciparum. Mol Biochem Parasitol 1995;1-10.

24. TragerW, Jensen J. Human malarial parasites in continue cultures. Science 1976;193:673-5.

25. Lambros C, Vanderberg J. Synchronization of Plasmodium falciparum increased erythrocytes stages in culture. J Parasitol 1979;8:47-9.

26. Rojas MO, Wasserman M. Temporal relationships on macromolecular synthesis during the asexual cell cycle of Plasmodium falciparum. Trans Roy Soc Trop Med Hyg 1984;79:792-6.

27. Wernsdorfer WH, Payne D. Drug sensitivity tests in malaria parasites. BullWHO 1980;58:1765-80.

28. Plowe CV, Djimde A, Wellems TE, Diop S, Kouriba B, Doumbo 0 . Community pyrimethamine-sulfadoxine use and prevalence of resistant Plasmodium falciparum genotypes in Mali: a model for deterring resistance. Am J Trop Med Hyg 1996;55:467-71.

29. Pecoulas PE, Abdallah B, Dje MK, Basco LK, Le-Bras $\mathrm{J}$, Mazabraud A. Use of a semi-nested PCR diagnosis test to evaluate antifolate of Plasmodium falciparum isolates. Mol Cell Probes 1995;9:391-7.

30. Gyang FN, Peterson DS, Wellems TE. Plasmodium falciparum: rapid detection of dihydrofolate reductase mutation that confer resistance to cycloguanil and pyrimethamine. Exp Parasitol 1992;74:470-2.

31. Triglia T, Wang P, Sims PFG, Hyde JE, Cowman AF. Allelic exchange at the endogenous genomic locus in Plasmodium falciparum proves the role of dihydropteroate synthase in sulfadoxine-resistant malaria. Embo $\mathrm{J}$ 1998;17:3807-15.

32. Snewin VA, Herrera M. Sanchez G, Schen A, Langsley G, Herrera S. Polymorphism of the alleles of the merozoite surface antigens MSA1 and MSA2 in Plasmodium 
falciparum wild isolates from Colombia. Mol Biochem Parasitol 1991;49:265-76.

33. Kaneko O, Kimura M, Kawamoto F, Ferreira MU,Tanabe K. Plasmodium falciparum: allelic variations in the merozoite surface protein 1 gene in wild isolates from Southern Vietnam. Exp Parasitol 1997;86:45-57.

34. Viriyakosol S, Siripoon N, Zhu XP, JarraW, Seugorn A. Plasmodium falciparum: selective growth of subpopulations from field samples following in vitro culture, as detected by the polymerase chain reaction. Exp Parasitol 1994;79:51725.

35. Bicki J, Basco LK, Ringwald P. Assessment of three in vitro tests and an in vivo test for chloroquine resistance in
Plasmodium falciparum clinical isolates. J Clin Microbiol 1998;36:243-7.

36. Krogstad, D. School of Public Health and Tropical Medicine. Department of Tropical Medicine, Tulane University. Comunicación personal, diciembre de 1997.

37. Schapira A, Bygbierg IC, Jepsen S, Bentzon MW. The susceptibility of Plasmodium falciparum to sulfadoxine and pyrimethamine correlation of in vivo and in vitro results. Am J Trop Med Hyg 1986;35:239-45.

38. Nguyen-Dinh P, Spencer HC, Chemangey-Masaba S, Churchill FC. Susceptibility of Plasmodium falciparum to pyrimethamine and sulfadoxine/pyrimethamine in Kimusu, Kenya. Lancet 1982;1:823-5. 


\title{
FE DE ERRATAS
}

Biomédica

1999;19(2):103-114

\section{Comparación de técnicas in vitro para detectar resistencia de Plasmodium falciparum a medicamentos}

\author{
Jacqueline Chaparro ${ }^{1}$, Moisés Wasserman ${ }^{2}$
}

Cuadro 1. Comportamiento de cepas de Plasmodium falciparum en la prueba radiométrica. Las casillas sombreadas corresponden a aislamientos resistentes y las no sombreadas a aislamientos sensibles, las cepas aparecen debajo de cada medicamento en orden descendente de resistencia (para quinina por ejemplo, la cepa FCR3 es la más resistente y $\mathrm{FCB} 1$ la más sensible). $C Q$, cloroquina; $A Q$, amodiaquina; $M Q$, mefloquina; $Q$, quinina; $\mathrm{H}$, halofantrina; $\mathrm{P}-\mathrm{S}$ pirimetaminasulfadoxina.

\begin{tabular}{|c|c|c|c|c|c|}
\hline \multicolumn{7}{|c|}{ MEDICAMENTO } \\
\hline CQ & AQ & MQ & Q & H & P-S \\
\hline Palo Alto & $7 \mathrm{G} 8$ & FCR3 & FCR3 & FCR3 & $7 G 8$ \\
\hline Camboya & Palo Alto & Palo Alto & Palo Alto & Camboya & T4 \\
\hline $7 G 8$ & FCR3 & FCB2 & FCB2 & T4 & Camboya \\
\hline T4 & Camboya & T4 & 7 G8 & 7 G8 & Palo Alto \\
\hline FCB2 & FCB2 & FCB1 & Camboya & Palo Alto & FCB2 \\
\hline FCB1 & FCB1 & $7 G 8$ & T4 & FCB1 & FCR3 \\
\hline FCR3 & T4 & Camboya & FCB1 & FCB2 & FCB1 \\
\hline
\end{tabular}

Cuadro 4. Mutaciones en la dihidropteroato sintetasa (DHPS)detectadas por PCR o restricción enzimática. Las columnas sombreadas corresponden a los genotipos mutantes, posiblemente asociados con resistencia a sulfadoxina.

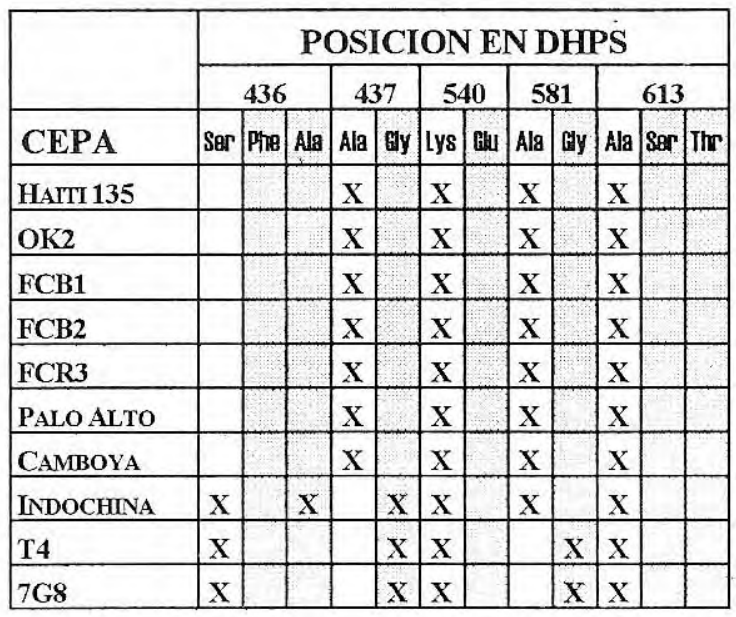

Cuadro 3. Mutaciones en la dihidrofolato reductasa (DHFR) detectadas por PCR o restricción enzimática. Las columnas sombreadas corresponden a los genotipos asociados con resistencia a Pirimetamina. $\mathrm{ND}=$ Dato no disponible.

\begin{tabular}{|c|c|c|c|c|c|c|c|c|c|c|c|c|}
\hline & \multicolumn{12}{|c|}{ POSICION EN DHIFR } \\
\hline 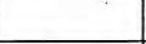 & \multicolumn{3}{|c|}{108} & \multicolumn{2}{|c|}{164} & \multicolumn{2}{|c|}{51} & \multicolumn{2}{|c|}{59} & 50 & \multicolumn{2}{|c|}{ BR } \\
\hline CEPA & Ser & Thr & Asn & 118 & Leu & Asn & 118 & Cys & Arg & Cys Arg & SI & No \\
\hline 3D7 & $\mathrm{X}$ & & & $\mathrm{x}$ & & $\mathrm{X}$ & & $\mathrm{X}$ & & ND & & D \\
\hline HAITI 135 & $\mathrm{x}$ & & & $\mathbf{x}$ & & $\mathbf{x}$ & & $\mathbf{X}$ & & $X$ & & $\mathbf{X}$ \\
\hline OK2 & $\mathbf{x}$ & & & $\mathbf{x}$ & & $\mathbf{X}$ & & $\mathbf{X}$ & & $\mathrm{X}$ & & $\mathrm{X}$ \\
\hline FCB1 & & $\mathbf{x}$ & & $\mathbf{X}$ & & $\mathrm{x}$ & & $\mathbf{x}$ & & $\mathbf{x}$ & & $\mathbf{x}$ \\
\hline FCB2 & & $\mathrm{x}$ & & $\mathrm{x}$ & & $\mathbf{x}$ & & $\mathrm{x}$ & & $\mathbf{x}$ & & $\mathrm{x}$ \\
\hline FCR3 & & $\mathbf{x}$ & & $\mathbf{x}$ & & $\mathbf{x}$ & & $\mathrm{x}$ & & $\mathrm{X}$ & & $\mathrm{x}$ \\
\hline PALO ALTO & & $\mathrm{x}$ & & $\mathbf{x}$ & & $\mathrm{X}$ & & $\mathbf{x}$ & & $\mathbf{X}$ & & $\mathbf{x}$ \\
\hline CAMBOYA & & $x$ & $\mathrm{X}$ & $\mathrm{x}$ & & $\mathrm{x}$ & & $\mathbf{x}$ & & $x$ & & $\mathrm{X}$ \\
\hline INDOCHINA & & & $\mathrm{X}$ & $\mathrm{x}$ & & & $\mathrm{X}$ & & $\mathrm{x}$ & $\mathrm{x}$ & & $\mathrm{X}$ \\
\hline $\mathrm{T} 4$ & & & $x$ & $\mathrm{x}$ & & & $\mathrm{x}$ & & $\mathrm{x}$ & $\mathrm{x}$ & & $\mathrm{X}$ \\
\hline $7 G 8$ & $x$ & & $\mathrm{X}$ & $\mathrm{x}$ & & & $\mathrm{X}$ & $\mathrm{x}$ & $\mathrm{X}$ & $\mathrm{x}$ & & $\mathrm{X}$ \\
\hline $\mathrm{V} 1 / \mathrm{s}$ & & & & & $\mathrm{X}$ & & $x$ & & $\mathrm{X}$ & ND & & D \\
\hline
\end{tabular}

1 Investigador científico, Grupo de Bioquímica, Instituto Nacional de Salud. Santafé de Bogotá, D.C., Colombia.

2 Profesor, Facultad de Ciencias, Universidad Nacional de Colombia; ilnvestigador científico, Grupo de Bioquímica, Instituto Nacional de Salud, Santafé de Bogotá, D.C., Colombia. 